\title{
Evaluation of some medicinal and aromatic plants to root-knot nematode, Meloidogyne javanica infection
}

\author{
El-Mesalamy A. F. ${ }^{\text {a }}$, Mahmoud N. A. , Anany A. E. , Abdel-Hafeez A. R. ${ }^{\text {a* }^{*}}$ \\ ${ }^{a}$ Agricultural Zoology and Nematology Department, Faculty of Agriculture, Al-Azhar University, Assiut, Egypt \\ ${ }^{b}$ Agricultural Zoology and Nematology Department, Faculty of Agriculture, Al-Azhar, University, Cairo, Egypt
}

\begin{abstract}
Eleven species of medicinal and aromatic plants were tested for their host suitability to root- knot nematode, Meloidogyne javanica under greenhouse conditions. The nematode species succeeded in developing and multiplying on almost the tested plants. Host suitability was assessed 60 days after inoculation on basis of root gall index (GI) and reproduction factor (Rf). Six species namely, Mentha piperita, Mentha viridis, Ocimum sanctum, Hibiscus sabdariffa, Hibiscus sabdariffa, Cymbopogon citratus were recorded as immune to $M$. javanica, no galls and nematode found on these plants. Whereas, Ocimum caryophyllatum and Mentha longifolia were considered as very resistant hosts with $\mathrm{Rf}$ values of 0.61 and 1.69. Tested species, Pimpinella anisum, considered had as moderately resistant with $\mathrm{Rf}$ value of 2.82 followed Ocimum basilicum regarded as slightly resistant with $\mathrm{Rf}$ value of 3.70. Though Rosmarinus officinalis had susceptible host to nematode infection with Rf value 8.43. Moreover, there was significant reduction in both shoot and root weights of the tested all plant species.
\end{abstract}

Keywords: Meloidogyne javanica, medicinal and aromatic plants, immune, very slightly, moderately resistant, susceptible. 


\section{Introduction}

The medicinal and aromatic plants are important as natural compounds in pharmaceutical, food and cosmetic and health, basic and applied research in the field of plant pests and diseases as an important step in the process of increasing the quantity and quality of medicinal plants products seems necessary. Among plant pathogens, nematodes parasites capable of high pathogenicity and the damage is estimated that annually about one hundred million dollars (Park et al., 2004). More nematode damage by nematodes genus Meliodogyne spp. is (Ripoll et al., 2003). Root-knot nematodes (Meliodogyne spp.) are spreading around the world. More and more of these nematodes in areas with warm weather short and winters can be found. Root-knot nematodes are over 2,000 species of plants, all crops; attack and global product agricultural production by about 5\% lower (Izadpanah et al., 2010). Over the years natural remedies in particular, basis medicinal plants and even in some cases the treatment was considered and while raw materials were used in the pharmaceutical industry. Pharmaceutical industry needs to obtain active ingredients of so much that it is possible to obtain from nature makes it impossible (Nasresfahani et al., 2015). Pandey et al. (2001) reported that the effect of the root- knot nematode (Meloidogyne incoguita) infection was different between lowest, moderate and high degree resistance by variation the variety of mint plants (Mentha spp.). Park et al. (2004) found that Achyranthes japonica Nakai, Atractylodes japonica
Koidz., Hibiscus manihot L., Ricinus communis L. and Sophora flavescens Ait were resistant to Meloidogyne hapla. Mostafa (2005) reported that Catharuthus alba, Catharamthu major, Damsis, Castor bean, Roselle and Garlic cv. chiense were highly resistant hosts for Meliodogyne incognita. Adegbite et al. (2008) reported that the decreasing agronomic parameters recorded for the untreated Roselle cv. The result of the stunting action of root-knot nematode (M. incognita). Baida et al. (2011) showed that Anethum graveolens (Dill), Pimpinella anisum (Fennel), Hyssopus offcinalis (Hyssop), Origanum majorana (Marjoram), Ocimum basilicum (Green Basil), Ocimum basilicum (Purple Basil) and Thymes common (Thyme) were resistant to $M$. incognita and M. javanica. Mostafa et al. (2014) showed that Ocimum basilicum ranked as tolerant host to Meloidogyne incognita. The aim of this study was to the reaction of eleven medicinal and aromatic plant species to the nematode Meloidogyn javanica.

\section{Materials and methods}

The Population of root- knot nematode, Meloidogyne javanica was maintained and propagated on tomato solanum lycopersicum cv. Rutgers. Nematode eggs were extracted from galled roots using in $1 \%$ the sodium hypochlorite $\mathrm{NaOCl}$ method (Hussey and Barker, 1973). Identification of Meloidogyne spp. was examined by microscope. Females were gently picked up and placed over a drop of lactophenol on a clean slide. Female posterior tail was cut with help of a sharp knife. Females were identified on the basis perineal pattern system (Eisenback 
et al., 1981). Three Seeds of each species of the medicinal and aromatic were planted in clay pots of $25 \mathrm{~cm}$ diameter, filled with mixture of loamy and sand soil $(2: 1 \quad \mathrm{v}: \mathrm{v})$ for two weeks. After germination plants in each pot were thinned to one healthy seedling and inoculated with approximately 3000 newly hatched juveniles (J2) of $M$. javanica per pot. Each inoculated plants was replicated four times. The uninoculated plants pots served as controls. All pots were randomizing on a bench in greenhouse. Plants were allowed to grow during the normal growing season at greenhouse temperature of $20 \pm 5{ }^{\circ} \mathrm{C}$, for 60 days or $30 \pm 5$ for 45 days after inoculation. At the end of the experiment roots of plants were carefully freed from soil and washed. The roots were then cut into hypochlorite $\mathrm{NaOCl}$ method and counted (Hussey and Barker, 1973). Females were gently picked up and placed over a drop of lactophenol on a clean slide. While the root gall index(RGI)and egg- mass index (EI) were estimated according to the scale given by (Taylor and Sasser, 1978) as follows: $0=$ no galls or egg-masses, $1=1-2$ galls or egg-masses, $2=3-10$ galls or egg-masses, $3=11-302$ galls, $4=31-1002$ galls or eggmasses and $5=>100$ galls or egg-masses. Host susceptibility was measured according to (Hadisoeganda and Sasser, 1982). As the follows: $0=$ Immune host (I), $0.0-1.0=$ highly resistant (HR), 1.1$3.0=$ very resistant $(\mathrm{VR}), \quad 3.1-3.5=$ moderately resistant (MR), 3.64.0=slightly resistant (SR) and 4.1-5.0 susceptible (S). Numbers of galls developmental stages with females, egg masses in the root system and numbers of eggs /egg-mass, rate of nematode (bulidup) were determined for each cultivars nematode treatment processed for nematode extraction (Southey 1964). Plant growth criteria involving fresh weights of both roots and shoots and their percentages of reduction were also calculated. Data were compared by Duncan's multiple- range test (Duncan's, 1955).

\section{Results and Discussion}

Eleven species medicinal and aromatic plants were tested for their susceptibility to root- knot nematode, $M$. javanica infection. Data presented in Table (1) showed that the behavior of $M$. javanica varied greatly according to the host type and the nematode species succeeded in developing and multiplying on almost the tested plants. Six species were classified as immune (I) (peppermint Mentha piperita, spearmint Mentha viridis, holy basil Ocimum sanctum, dark roselle Hibiscus sabdariffa, pastel roselle Hibiscus sabdariffa and lemongrass Cymbopogon citratus), horsemint Mentha longifolia and pink basil Ocimum caryophyllatum as very resistant (VR), anise Pimpinella anisum as moderately resistant (MR), sweet basil Ocimum basilicum as slightly resistant (SR). While, rosemary Rosmarinus officinalis was classified as susceptible (S) host gained the highest values of nematode in egg production and final population among the tested plants. The calculated values of rate nematode reproduction and percentages of egg production were plants (1.69 \& 17.47\%) horsemint (VR) and pink 
basil (VR) $(0.61 \& 4.84 \%),(2.82 \&$ $32.78 \%)$ anise (MR), (3.70 \& 43.44\%) sweet Basil (SR). On the other hand, $M$. javanica failed to reproduce and multiply on plants peppermint $M$. piperita, spearmint $M$. viridis, holy basil $O$. sanctum, dark roselle $H$. sabdariffa, pastel roselle $H$. sabdariffa and lemongrass $C$. citratus. Whereas, rosemary R.officinalis had the highest values Numbers of galls, developmental stages with females, egg masses in the root system and numbers of eggs legg mass, rate of nematode reproduction and percentage of egg production recorded that $(8.43 \& 100 \%)$ of nematode criteria.

Table (1): Susceptibility of some medicinal and aromatic plants species to the root - knot nematode Meloidogyne javanica under greenhouse conditions.

\begin{tabular}{|c|c|c|c|c|c|c|c|c|c|c|c|}
\hline \multicolumn{2}{|c|}{ Medicinal and Aromatic plants species } & \multirow[b]{2}{*}{ 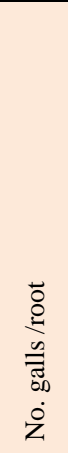 } & \multicolumn{5}{|c|}{ Nematode population } & \multirow[b]{2}{*}{ 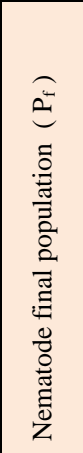 } & \multirow[b]{2}{*}{ 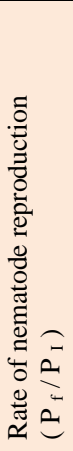 } & \multirow[b]{2}{*}{ 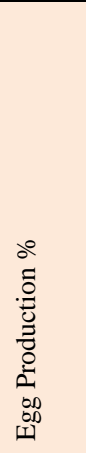 } & \multirow[b]{2}{*}{ 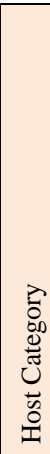 } \\
\hline Common name & Scientific name & & 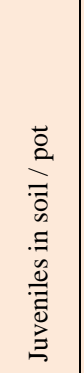 & 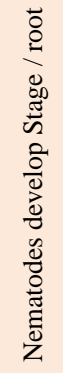 & 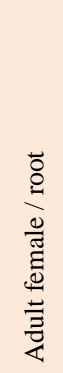 & 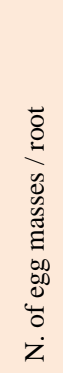 & 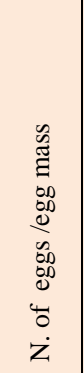 & & & & \\
\hline Peppermint & Mentha piperita & $0 \mathrm{f}$ & $0 \mathrm{c}$ & $0 \mathrm{c}$ & $0 \mathrm{f}$ & $0 \mathrm{~d}$ & $0 \mathrm{~d}$ & 0 & 0.00 & 0.00 & $\mathrm{I}$ \\
\hline Spearmint & Mentha viridis & $0 \mathrm{f}$ & $0 \mathrm{c}$ & $0 \mathrm{c}$ & $0 \mathrm{f}$ & $0 \mathrm{~d}$ & $0 \mathrm{~d}$ & 0 & 0.00 & 0.00 & $\mathrm{I}$ \\
\hline Horsemint & Mentha longifolia & $22 \mathrm{~d}$ & $691 \mathrm{a}$ & $2 \mathrm{bc}$ & $19 \mathrm{~d}$ & $19 \mathrm{c}$ & $230 \mathrm{c}$ & 5082 & 1.69 & 17.47 & VR \\
\hline Sweet basil & Ocimum basilicum & $49 \mathrm{~b}$ & $194 \mathrm{~b}$ & $6 \mathrm{~b}$ & $42 \mathrm{~b}$ & $41 \mathrm{~b}$ & $265 \mathrm{c}$ & 11107 & 3.70 & 43.44 & SR \\
\hline Pink basil & Ocimum caryophyllatum & $12 \mathrm{e}$ & $623 \mathrm{a}$ & $4 \mathrm{bc}$ & $7 \mathrm{e}$ & $5 \mathrm{~d}$ & $242 \mathrm{c}$ & 1844 & 0.61 & 4.84 & VR \\
\hline Holy basil & Ocimum sanctum & $0 \mathrm{f}$ & $0 \mathrm{c}$ & $0 \mathrm{c}$ & $0 \mathrm{f}$ & $0 \mathrm{~d}$ & $0 \mathrm{~d}$ & 0 & 0.00 & 0.00 & I \\
\hline Dark roselle & Hibiscus sabdariffa & $0 \mathrm{f}$ & $0 \mathrm{c}$ & $0 \mathrm{c}$ & $0 \mathrm{f}$ & $0 \mathrm{~d}$ & $0 \mathrm{~d}$ & 0 & 0.00 & 0.00 & $\mathrm{I}$ \\
\hline Pastel roselle & Hibiscus sabdariffa & $0 \mathrm{f}$ & $0 \mathrm{c}$ & $0 \mathrm{c}$ & $0 \mathrm{f}$ & $0 \mathrm{~d}$ & $0 \mathrm{~d}$ & 0 & 0.00 & 0.00 & $\mathrm{I}$ \\
\hline Lemongrass & Cymbopogon citratus & $0 \mathrm{f}$ & $0 \mathrm{c}$ & $0 \mathrm{c}$ & $0 \mathrm{f}$ & $0 \mathrm{~d}$ & $0 \mathrm{~d}$ & 0 & 0.00 & 0.00 & $\mathrm{I}$ \\
\hline Rosemary & Rosmarinus officinalis & $85 \mathrm{a}$ & $196 \mathrm{~b}$ & $14 \mathrm{a}$ & $72 \mathrm{a}$ & $66 \mathrm{a}$ & $379 \mathrm{a}$ & 25296 & 8.43 & 100.00 & $\mathrm{~S}$ \\
\hline Anise & Pimpinella anisum & $30 \mathrm{c}$ & $245 \mathrm{~b}$ & $3 \mathrm{bc}$ & $27 \mathrm{c}$ & $25 \mathrm{c}$ & $328 \mathrm{~b}$ & 8475 & 2.82 & 32.78 & MR \\
\hline
\end{tabular}

Means in each column followed by the same letter(s) are not significantly different by $(\mathrm{p}=0.05)$ according to Duncan's multiple range test.

The influence of the root-knot nematode $M$. javanica on plant growth of fresh weights of shoots and roots of eleven plant species as well as percentage reductions (expressed here as fresh weight shoots and roots) when compared with healthy once were registered in Table (2).The highest reduction in shoots and roots fresh weights were recorded in rosemary $R$. officinalis $(28.69 \%$ \& $45.57 \%$ ) and sweet basil $O$. basilicum $(24.17 \%$ \& $34.65 \%)$ were highly significantly affected by the nematode infection when compared with their controls. The percentage of reductions in shoots and roots fresh weights in such plants were anise $P$. anisum $(16.77 \%$ \& $23.43 \%)$, horsemint (12.94\% \& 19.08\%) 
and pink basil O. caryophyllatum (13.52\% \& 16.37\%).

Table (2): Plant growth of some medicinal and aromatic plants species as influenced with the infection of the root-knot nematode Meloidogyne javanca under greenhouse conditions.

\begin{tabular}{|c|c|c|c|c|c|c|c|c|c|c|c|c|c|}
\hline \multicolumn{2}{|c|}{ Medicinal and aromatic plants species } & \multicolumn{6}{|c|}{ Length $(\mathrm{cm})$} & \multicolumn{6}{|c|}{ Fresh weight (gm) } \\
\hline \multirow[b]{2}{*}{ Common name } & \multirow[b]{2}{*}{ Scientific name } & \multicolumn{3}{|c|}{ Shoot } & \multicolumn{3}{|c|}{ Root } & \multicolumn{3}{|c|}{ Shoot } & \multicolumn{3}{|c|}{ Root } \\
\hline & & 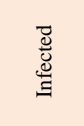 & 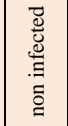 & 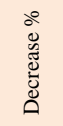 & $\begin{array}{l}\vec{J} \\
\stackrel{\Xi}{J} \\
\stackrel{ٍ}{\Xi}\end{array}$ & 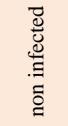 & $\begin{array}{l}0 \\
0 \\
0 \\
\tilde{\Xi} \\
\tilde{d} \\
\tilde{D} \\
0\end{array}$ & 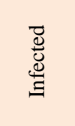 & 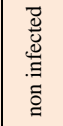 & 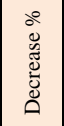 & $\begin{array}{l}\vec{\Xi} \\
\stackrel{\Xi}{\circlearrowright} \\
\Xi\end{array}$ & $\begin{array}{l}\vec{\Xi} \\
\stackrel{\Xi}{J} \\
. \\
\Xi \\
\Xi \\
\Xi\end{array}$ & 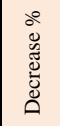 \\
\hline Peppermint & Mentha piperita & 22.25 & 23.00 & 3.26 & 8.625 & 8.50 & -1.47 & 1.45 & 1.47 & 1.19 & 1.32 & 1.34 & 1.32 \\
\hline Spearmint & Mentha viridis & 33.25 & 33.25 & 0.00 & 35.75 & 35.50 & -0.70 & 12.25 & 12.30 & 0.40 & 18.42 & 18.45 & 0.13 \\
\hline Horsemint & Mentha longifolia & $25.62 *$ & 30.62 & 16.31 & 10.75 & 12.32 & 12.74 & 2.96 & 3.40 & 12.94 & 3.15 & 3.76 & 19.08 \\
\hline Sweet basil & Ocimum basilicum & $37.87 * *$ & 50.25 & 24.62 & $17.87 * *$ & 22.50 & 20.55 & $11.01 *$ & 14.52 & 24.17 & $1.51^{*}$ & 2.04 & 34.65 \\
\hline Pink basil & Ocimum caryophyllatum & $32.50^{* *}$ & 37.75 & 13.90 & 22.00 & 25.50 & 13.72 & 8.95 & 10.35 & 13.52 & 1.29 & 1.51 & 16.37 \\
\hline Holy basil & Ocimum sanctum & 48.50 & 47.75 & -1.57 & 45.12 & 45.25 & 0.27 & 10.08 & 10.16 & 0.78 & 2.42 & 2.50 & 2.98 \\
\hline \begin{tabular}{|l} 
Dark roselle \\
\end{tabular} & Hibiscus sabdariffa & 42.50 & \begin{tabular}{|l|}
42.25 \\
\end{tabular} & -0.59 & 51.25 & 51.50 & 0.48 & 15.32 & 15.35 & 0.16 & 3.59 & 3.65 & 1.67 \\
\hline Pastel roselle & Hibiscus sabdariffa & 48.62 & 48.37 & -0.52 & 47.25 & 47.50 & 0.52 & 15.42 & 15.45 & 0.16 & 3.82 & 4.07 & 6.40 \\
\hline Lemongrass & Cymbopogon citratus & 80.50 & 82.50 & 2.42 & 33.25 & 33.75 & 1.48 & 13.30 & 13.42 & 0.83 & 4.08 & 4.12 & 0.91 \\
\hline Rosemary & Rosmarinus officinalis & $19.50 * *$ & 31.75 & 38.58 & $14.00 *$ & 18.62 & 24.81 & $4.39 *$ & 6.16 & 28.69 & 3.64 & 5.31 & 45.57 \\
\hline Anise & Pimpinella anisum & $39.50 * *$ & 48.25 & 18.13 & 5.75 & 7.00 & 17.85 & $1.24 *$ & 1.49 & 16.77 & 1.28 & 1.58 & 23.43 \\
\hline
\end{tabular}

* Significant at 0.05 level of probability. ** Highly significant at 0.01 level of probability.

Whereas, the lowest reductions in shoots and roots fresh weights were recorded on spearmint $M$. viridis, lemongrass $C$. citratus, dark roselle $H$. sabdariffa, pastel roselle $H$. sabdariffa, peppermint $M$. piperita, holy basil $O$. sanctum were immune to $M$. javanica which showed that horsemint $M$. longifolia and pink basil $O$. caryophyllatum as very resistant (VR), anise $P$. anisum as moderately resistant (MR), sweet basil $O$. basilicum as slightly resistant (SR). Except rosemary was susceptibility (S). These results are in agreement with those of Moura et al. (1990), Moreno et al. (1992), Vawdrey and Stirling (1992), Baida et al. (2011), Mostafa (2005) and Mostafa et al. (2014).

\section{References}

Adegbite, A. A., Agbaje, G. O. and Abidoye, J. (2008), "Assessment of yield loss of roselle (Hibiscus sabdariffa L.) due to root-knot nematode, Meloidogyne incognita under field conditions", Journal of Plant Protection Research, Vol. 48 No. 3, pp. 267-273.

Baida, F. C., Santiago, D. C., Vidal, L. H. I., Baida, L. C. and Stroze, C. T. (2011), "Medicinal plants hosting ability for nematode Meloidogyne javanica and M. incognita", Nematropica, Vol. 41, pp. 151-153.

Duncan's, D. B. (1955), "Multiple ranged multiple F-test", Biometrics, Vol. 11, pp. $1-47$.

Eisenback, J. D., Hirschmann, H., Sasser, J. N. and Triantaphyllou, A. C. (1981), A guide to the four most common species of root-knot nematode (Meloidogyne spp.) with a pictorial key, US Agency for 
International Development. Raleigh, North Carolina; Dep. of Plant Pathology and Genetics, North Carolina State University USA.

Hadisoeganda, W. W. and Sasser, J. N. (1982), "Resistance of tomato, bean, southern pea and garden pea cultivars to root-knot nematodes based on host suitability", Plant Disease, Vol. 66, pp. 145-150.

Hussey, R. S. and Barker, K. R. (1973), "A comparison on methods of collecting inocula of Meloidogyne spp. including a new technique", Plant Disease Report, Vol. 57, pp.1925-1928.

Izadpanah, K., Ashkan, S. M., BaniHashemi, R., Rahimian, H. and Minassian, A. (2010), Plant Pathology, fifth edition, Agrios J. A. (Ed.), Academic Press, Elsevier, USA.

Moreno, J. E., Rich, J. R., French, E. C., Priney, G. M. and Dunn, R. A. (1992), "Reaction of selected herbs to three Meloidogyne spp.", Nematropica, Vol. 22, pp. 217-225.

Mostafa Fatma, A. M., Refaei, A. R., Khalil, A. E. and El-Deriny Marwa, M. (2014), "Host suitability of certain ornamental plants to the root knot nematode, Meloidogyne incognita and reniform nematode, Rotylenchulus Reniformis under greenhouse conditions", International Journal of Advanced Research, Vol. 2 No. 12, pp. 33-42.
Mostofa, Z. W. (2005), Ecological and Pathological Studies on Nematode Associated with Certain Medicinal and Aromatic Plants. PhD Thesis, Faculty of Agriculture, Al-Azhar University, Cairo, Egypt.

Moura, R. M., de Oliveira-Regis, E. M. and de Moura, A. M. (1990), "Reactions of ten plant species, some producers of essential oils, in relation to Meloidogye incognita race land $M$. javanica parasitism in mixed population", Nematologia Brasileira, Vol. 14, pp. 39-44.

Nasresfahani, M., Kermani, A. M., Zargani, M. and Alizadeh, M. (2015), "Evaluation nematode of some medicinal plant in Isfahan", Indian Journal of Fundamental and Applied Life Sciences, Vol. 5, pp. 2665-2674.

Pandey, R., Patra, N. and Paisdy, R. (2001), "Screening mint (Mentha spp.) assessions root-knot nematode infection", Journal of Spices and Aromatic Crops, Vol. 10, pp. 55-56.

Park, S. D., Kim, J. C. and Khan, Z. (2004), "Host status of medicinal plants for Meloidogyne hapla", Nematropica, Vol. 34, pp. 39-43.

Ripoll, C., Favery, B., Lecomte, P., Van Damme, E., Peumans, W., Abad, P. and Jouanin, L. (2003), "Evaluation of the ability of lectin from snowdrop (Galanthus nivalis) to protect plants against root-knot nematodes", Plant Science, Vol. 164 No. 4, pp. 517-523. 
Southey, I. F. (1964), Laboratory methods for work with plant and soil nematodes, $5^{\text {th }}$ ed., No. 2, Technical bulletin - Ministry of Agriculture, Fisheries and Food, London, United Kingdom.

Taylor, A. L. and Sasser, J. N. (1978), Biology, identification and control of root-knot nematodes (Meloidogyne species). Department of Plant Pathology, North Carolina State University: United States Agency for International Development, USA, pp. 111.
Vawdrey, L. L. and Stirling, G. R. (1992), Reaction of kenaf and roselle grown in the Burdekin River irrigation area to root-knot nematodes. Australasian Plant Pathology, Vol. 21 No. 1, pp. 8-12. 